International journal of Advanced Biological and Biomedical Research

Available online at http://www.ijabbr.com

Volume 7, Issue 1 (2019) pp. 12-18

Review Article

\title{
Physiology of parturition
}

\author{
Amir Hussein Asgari safdar1* , Hussein Daghigh Kia², Ramin Farhadi' \\ ${ }^{1}$ M.Sc. students of animal physiology, Faculty of Agriculture, University of Tabriz, Tabriz, \\ Iran. \\ ${ }^{2}$ Assistant Prof, Department of Animal Science, Faculty of Agriculture, University of Tabriz, \\ Tabriz, Iran. \\ *Corresponding Author E-mail: Amir9002001@yahoo.com
}

Received: 14 October 2018, Revised: 23 December 2018, Accepted: 25 December 2018

\begin{abstract}
Labor is a physiological event involving a sequential, integrated set of changes within the myometrium, deciduas, and uterine cervix that occur gradually over a period of days to weeks. Biochemical connective tissue changes in the uterine cervix appear to precede uterine contractions and cervical dilation, and all of these events usually occur before rupture of the fetal membranes. In other word Parturition is the process of delivery of the fully grown fetus on the completion of the normal pregnancy period.
\end{abstract}

Key words: Parturition, Labor, Hormones.

\section{Introduction}

Labor is characterized by an increase in myometrial activity or, more precisely, a change in the myometrial contractility pattern from "contractures"(long-lasting, low frequency activity) to contractions" (high intensity, high frequency activity) (Thorburn et al., 1997), resulting in effacement and dilatation of the uterine cervix. In other words, Parturition is the process of delivery of the fully-grown fetus on the completion of the normal pregnancy period. Parturition is an interesting biological process in the sense that the uterus that was quiescent during the entire pregnancy starts contracting and the cervix that was tightly contracted relax sufficiently to allow the passage of the young one to the world outside the mother's womb, passing through the birth canal (which is formed by the uterus, cervix and vagina within the pelvic bones and their other attachments).

\section{Physiological Phases Of Myometrial Activity}

The regulation of uterine activity during pregnancy can be divided into four distinct physiologic phases (Huber et al., 2005 and Jenkin et al., 2004): Phase 0: inhibitors active during pregnancy the uterus is maintained in a state of functional quiescence through the action of various putative inhibitors including, but not limited to:

- Progesterone 
- Prostacyclin (prostaglandin I-2)

- Relaxin

- Parathyroid hormone-related peptide Nitric oxide

- Calcitonin gene-related peptide

- Adrenomedullin

- Vasoactive intestinal peptide.

Phase 1: myometrial activation - as term approaches the uterus becomes activated in response to uterotropins, such as estrogen. This phase is characterized by increased expression of a series of contraction-associated proteins (CAPs) (including myometrial receptors for prostaglandins and oxytocin), activation of specific ion channels, and an increase in connexin-43 (a key component of gap junctions). An increase in gap junction formation between adjacent myometrial cells leads to electrical synchrony within the myometrium and allows for effective coordination of contractions.

Phase 2: stimulatory phase - Following activation, the "primed" uterus can be stimulated to contract by the action of uterotonic agonists, such as the stimulatory prostaglandins E2 and F2 alpha and oxytocin.

Phase 3: involution - Involution of the uterus after delivery occurs during phase 3 and is mediated primarily by oxytocin.

\section{Prepartum signals for parturition initiation}

The initiation of parturition in most domestic animals continues to be only partially understood. It is fascinating that on completion of events necessary to render a young one capable of independent life Outside the mother's uterus, closely coordinated changes occur in the fetus and mother resulting into delivery of the fetus by the act of parturition. Possibly the initial mechanism for the timing of birth is encoded in the fetal genome and is closely linked to, and activated when certain prerequisite developmental events have occurred in the fetus (Jenkin et al., 2004). The possible factors that help in initiation and the act of parturition include physical, biochemical and neuro endocrine (Table 1) factors.

Table -1: Possible factors responsible for initiation of parturition

\begin{tabular}{lcc}
\hline Physical factors & Effect \\
\hline 2.increase in fetal size & $\begin{array}{c}\text { Increase in uterine irritability } \\
\text { Reversal of progesterone block } \\
\text { Reflex to reduce size by fetal } \\
\text { expulsion }\end{array}$ \\
$\begin{array}{c}\text { 3.fatty degeneration of placenta \& } \\
\text { presence of infarcts }\end{array}$ & $\begin{array}{c}\text { Leads to interference in fetal } \\
\text { nutrition \& separation process of } \\
\text { fetus from uterus }\end{array}$ \\
& \\
\hline
\end{tabular}




\section{Hormones Involved In The Parturition}

\section{Prostaglandins}

Prostaglandins are predominantly paracrine/autocrine hormones (i.e., they act locally at their site of production on contiguous cells). An increase in uterine prostaglandin biosynthesis is a consistent element in the transition into labor (Keirse, 1979), and is probably common to all species (Liggins, 1981).

\section{Progesterone:}

Administration of a progesterone receptor antagonist or removal of the readily induces abortion in early pregnancy (before 7 weeks of gestation), corpus luteum [suggesting that progesterone is necessary for early pregnancy maintenance. Administration of exogenous progesterone after early lutectomy prevents abortion, further supporting the hypothesis that ovarian progesterone production is essential in maintenance of early pregnancy. Placental progesterone production becomes important between 7 and 9 weeks, and the placenta is the dominant source of progesterone thereafter. However, the role of progesterone in late pregnancy is not as well defined.

\section{Estrogen:}

The placenta is the primary source of estrogen biosynthesis during pregnancy. Estrogens do not themselves cause myometrial contractions, and maternal administration of estradiol to rhesus macaques from 130 days of gestation has no effect on length of pregnancy (Novy et al., 1983). Instead, estrogens act by up regulating myometrial gap junctions (Garfield et al., 1980) and uterotonic receptors (including L-type calcium channels and oxytocin receptors) (Fuchs, 1986 a), thereby enhancing the capacity of the myometrium to generate contractions.

\section{PGF 2alpha}

Enhances myometrial contractions, induces luteolysis and the release/secretion of relaxin.

\section{Oxytocin}

Oxytocin is a peptide hormone synthesized in the hypothalamus and released from the posterior pituitary in a pulsatile fashion. Its biologic half-life is approximately three to four minutes, but appears shorter when higher doses are infused. Oxytocin is inactivated in the liver and kidney, although during pregnancy it is primarily degraded by placental oxytocinase. Oxytocin is the most potent endogenous uterotonic agent, and is capable of stimulating uterine contractions at intravenous infusion rates of 1 to $2 \mathrm{mU} / \mathrm{min}$ at term (Fuchs et al., 1984b and Zeeman et al., 1997). The frequency and amplitude of oxytocininduced uterine contractions are identical to those occurring during spontaneous labor. 


\section{Glucocorticoids}

These hormones have several actions that can also help prepare the uterus for labor. Glucocorticoids act directly to up regulate prostaglandin production in fetal membranes at term (Jenkin et al., 2004 and Potestio et al., 1988). Cortisol appears to stimulate expression of placental (but not hypothalamic) $\mathrm{CRH}$ in vitro [66]. In addition, cortisol enhances amnionic cyclooxygenase to enhance prostaglandin synthesis and inhibits chorionic prostaglandin dehydrogenase activity, thereby preventing prostaglandin metabolism (Challis et al., 1995 and Jenkin et al., 2004).

\section{Parathyroid hormone-related peptide}

Parathyroid hormone-related peptide is a potent smooth muscle relaxant capable of inhibiting oxytocin-induced contractions in baboons (Pitera et al., 1998). It is unclear whether it has a physiologically important role in maintaining uterine quiescence prior to the onset of labor.

\section{Relaxin}

Relaxin is a member of the insulin-like growth factor family of proteins. Plasma levels are highest at 8 to 12 weeks of gestation and thereafter decline to low levels, which persist until term (MacLennan et al., 1986). The primary source of relaxin is thought to be the corpus luteum.

\section{Parturition}

It is very important that during parturition the animal moves smoothly through the three stages of parturition $n$ a reasonable amount of time to ensure a safe and normal birth. The first stage of parturition is known as the Preparatory Stage. It is during this stage, as is evident from the name that the female prepares to give birth. Some signs that parturition is near can be observed during this stage. In addition, there may be mucus discharge from the vulva, decreased body temperature, filling of mammary glands with milk, and mild straining. Behavioral signs include nesting behavior and possibly stealing other newborns in the herd. The second stage of parturition is the Expulsion Stage. It is at this point that the walls of the uterus begin to contract more frequently and with increased force, thus pushing the fetus into the birth canal. When the contractions become strong enough, the fetus is actually forced out of the female's body, hence the name the Expulsion Stage. Once an animal has entered this stage, delivery should occur fairly soon; otherwise, there may be difficulties preventing normal delivery. Again, the standard amount of time allowed for a normal birth can differ between species. The final stage of parturition is the Cleaning Stage. It is at this point in the process that the afterbirth, or the placenta, is expelled from the body. In order for the animal to make a normal, healthy recovery from parturition, the afterbirth must be expelled. If the fetal membranes and fluid remain in the animal, they can become infected and lead to serious illness and possible death of the mother. 


\section{The Role of the Fetus on Beginning:}

Figure 1. The on beginning of

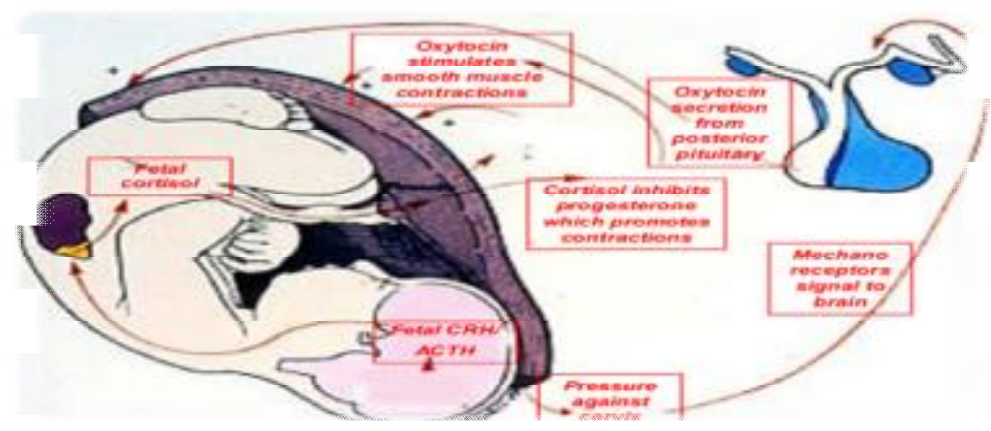

role of fetus

labor

Considerable evidence suggests that in most viviparous animals the fetus controls the timing of onset of labor (Thorburn et al., 1997 and Pitera et al., 1998 , Fig 1). During the Hippocratic period, the fetus was thought to be positioned head down at term so it could kick its legs up against the fundus of the uterus, thereby propelling itself through the birth canal. While we have moved away from this simple and mechanical view of labor, the factors responsible for the initiation and maintenance of labor at term are not well defined. Initial investigations focused on endocrine events, such as changes in the profile of circulating hormone levels in the maternal and fetal circulations. Subsequent studies have concentrated on the dynamic biochemical dialogue between the fetus and mother (paracrine/autocrine events) in an attempt to understand the molecular mechanisms that regulate such interactions. The genetic regulations of the molecular events that occur during parturition are also being investigated [Huber et al., 2005].

Pathways to parturition: this section was indicated in Figure 2.

\section{Pathways to Parturition}

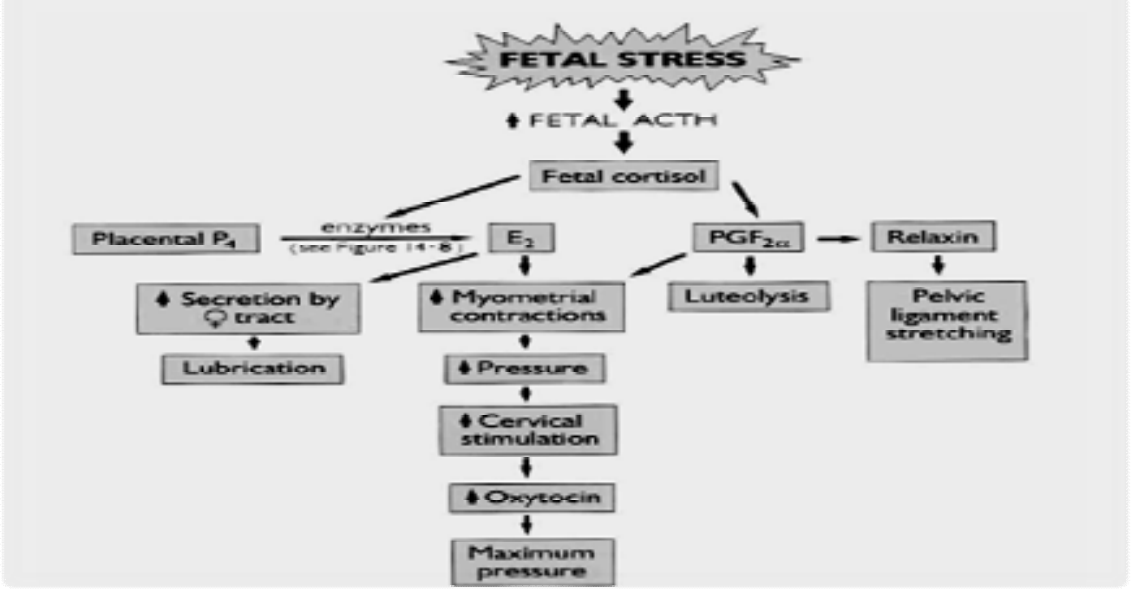

Figure 2. pathway to parturition 


\section{Interaction between: Prostaglandins, Cytokines and Oxytocin}

Observations suggest that prostaglandins are positive regulators of oxytocin receptor expression, that the uterotonic action of prostaglandins depends partly on oxytocin action, and that prostaglandins, but not oxytocin, are directly involved in the initiation of labor and the role of cytokines is in direct relation on performance of PG.

\section{Dystocias (Difficult births)}

Dystocia may also be caused by maternal reproductive problems such as infection, poor nutrition or obesity where excess fat in the birth canal reduces the area for the fetus to pass through (Fig 3).
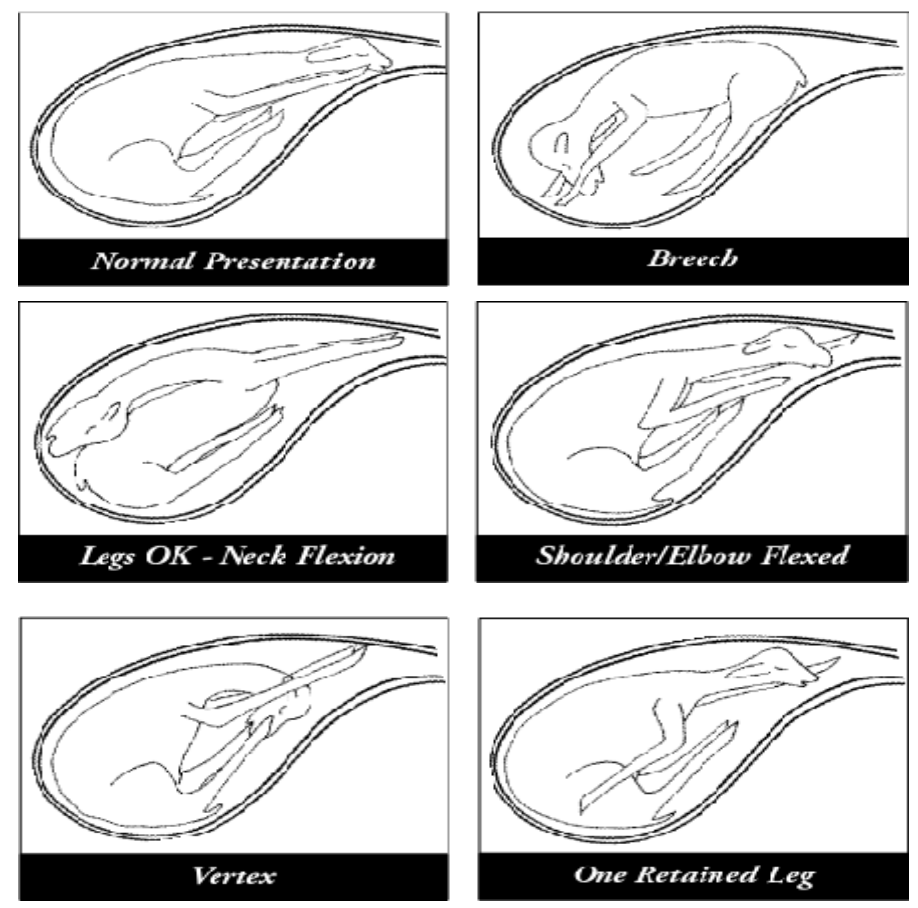

Figure 3. Different modes of abnormal fetal position in ruminants

\section{References:}

Challis, JR, Matthews, SG, Van Mier, C, Ramirez, MM (1995). The placental corticotrophinreleasing hormone-adreno-corticotrophin axis. Placenta, 16:481.

Fuchs, AR. The role of oxytocin in parturition (1986 a). In: The Physiology and Biochemistry of the Uterus in Pregnancy and Labour, Huszar, G, (Ed), CRC Press, Boca Raton, Florida, p. 163.

Fuchs, AR, Fuchs, F. Endocrinology of human parturition (1984 b). A review. Br J Obstet Gynaecol, 91:948. 
Garfield, RE, Kannan, MS, Daniel, EE (1980). Gap junction formation in myometrium: control by estrogens, progesterone, and prostaglandins. Am J Physiol, 238:C81.

Huber, A, Hudelist, G, Czerwenka, K, et al (2005). Gene expression profiling of cervical tissue during physiological cervical effacement. Obstet Gynecol, 105:91.

Jenkin G, Young IR (2004). Mechanisms responsible for parturition; the use of experimental models. Anim Reprod Sci 82 - 85: 567-81.

Keirse, MJNC (1979). Endogenous prostaglandins in human parturition. In: Human Parturition. Keirse, MJNC, Anderson, ABM, Bennebroek-Gravenhorstm, J, (Eds), Leiden University Press, Leiden. p. 101.

Liggins, GC (1981). Initiation of parturition. In: Fetal Endocrinology, Novy, MJ, Resko, JA, (Eds), Academic Press, New York, p. 211.

MacLennan, AH, Nicolson, R, Green, RC (1986). Serum relaxin in pregnancy. Lancet, 2:241.

Nathanielsz, PW, Giussani, DA, Wu, WX (1997). Stimulation of the switch in myometrial activity from contractures to contractions in the pregnant sheep and nonhuman primate. Equine Vet J Suppl, :83.

Novy, MJ, Walsh, SW (1983). Dexamethasone and estradiol treatment in pregnant rhesus macaques: effects on gestational length, maternal plasma hormones, and fetal growth. Am J Obstet Gynecol, 145:920.

Pitera, AE, Smith, GC, Wentworth, RA, Nathanielsz, PW (1998). Parathyroid hormonerelated peptide (1 to 34 ) inhibits in vitro oxytocin-stimulated activity of pregnant baboon myometrium. Am J Obstet Gynecol, 179:492.

Potestio, FA, Zakar, T, Olson, DM (1988). Glucocorticoids stimulate prostaglandin synthesis in human amnion cells by a receptor-mediated mechanism. J Clin Endocrinol Metab, $67: 1205$.

Spitz, IM, Bardin, CW (1993). Mifepristone (RU 486) - a modulator of progestin and glucocorticoid action. N Engl J Med, 329:404.

Thorburn, GD, Challis, JRG, Robinson, JS (1977). The endocrinology of parturition. In: Cellular Biology of the Uterus, Wynn, RM (Ed), Plenum Press, New York, p. 653.

Zeeman, GG, Khan-Dawood, FS, Dawood, MY (1997). Oxytocin and its receptor in pregnancy and parturition: Current concepts and clinical implications. Obstet Gynecol, 89:873.

How to cite this article: Amir Hussein Asgari safdar, Hussein Daghigh Kia, Ramin Farhadi, Physiology of parturition. International Journal of Advanced Biological and Biomedical Research, 2019, 7(1), 12-18. http://www.ijabbr.com/article 33589.html 